\title{
Caso Semmelweis: Al Filo del Paradigma Médico Moderno
}

\author{
Rita Bocó \\ Gisela Bulanikian
}

\begin{abstract}
Resumo
0 presente trabalho realizou uma análise da biografia de Ignaz Semmelweis (18181865), que mostrou que a elevada porcentagem de morte causada por febre puerperal fora causada por agentes infecciosos transmitidos pelas mãos contaminadas dos médicos. 0 que fez de Semmelweis uma pessoa mal vista ou mal compreendida entre seus colegas? Focalizar esse caso dentro do processo histórico da prática médica, no surgimento das primeiras noções de higiene e saúde pública, permitiu identificar o que fora questionado pela posição desafiante de Semmelweis. A descoberta de Semmelweis surgiu no século XIX, em um contexto europeu de revoltas e mudança sócio-políticas, no momento da construção de uma teoria médica e de um paradigma científico que legitimou e envolveu a luta entre a ortodoxia e heterodoxia. 0 estudo do caso de Semmeweiss permite observar, de um novo ponto de vista, a historia de um indivíduo que questionou os paradigmas da ciência que governavam o modelo médico de seu tempo. Na sua história, são manifestas as contradições de um sistema médico em formação, sancionado como a única forma científica e eficaz de cuidar da saúde e da doença. Embora fora uma figura controvertida em seu tempo, transformou-se no precursor da assepsia abrindo possibilidades para uma compreensão nova e original das doenças infecciosas.

Palavras-chave: Biografia. Prática médica. Construção social. Processo histórico. Processo saúde e doença.
\end{abstract}

\begin{abstract}
Through this pages, we made an analysis on Semmelweis biography, which showed that the high death rate for women after giving birth was caused by infectious agents transmitted by contaminated hands of the doctors. From the beginning, we wondered what made of Semmelweis an accursed person. An insight to the first years of medical practice, when the professional knowledge was constructed and the concept of public health and hygienic arose, let us see what Semmelweis faced. Semmelweis discovery emerged during a historical period marked out by political instability and change, at the same time of the modern medical theory construction and the arising of a scientific


paradigm, which validated and involved a dispute between orthodoxy and heterodoxy inside the medicine limits in the middle of the nineteenth century. In this way, it shows the opposition between the arising knowledge and the medical orthodoxy that he challenged it. We will try to analyze, from a new point of view, the doctor Semmelweis's history, considered as a case of study about an individual who questioned the paradigms of the contemporary orthodox science. He pointed out an anomaly in the practice of the medicine. In the history of Semmelweis we can see the contradictions of the arising medical knowledge and its practice that was trying to legitimate itself as the only scientific and accurate way of cure. Indeed he was questioned and damned. In spite of that, he became the father of the asepsis through the history. He opened new possibilities for an original understanding of infectious diseases.

Key words: Biography. Medical practice. Social construction. Historical process. Process Health and illness.

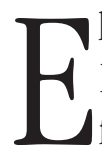
I caso Semmelweis nos muestra un personaje atrapado, por la idea del progreso lineal y positivo heredado del Siglo de las Luces y, por el otro, por la idea que se va formando a lo largo del siglo XIX con el romanticismo hegeliano de criterios más científicos, impregnados en la fe del progreso. Característico de la mentalidad burguesa es operar una disolución entreel hombre y la naturalezay, por lo tanto, entre la realidad sensible y la realidad sobrenatural. Si la primera operación convierte a la naturaleza en un objeto de conocimiento parael hombre, su consecuenciaseráconocer apartir de la experiencia. Ampliar las dimensiones de lo real será la tendencia que acompaña el conocimiento de lo diverso (Romero, 1993). Para entender el caso en cuestión, observaremos las definiciones culturales de enfermedad y curación de suépocaen comparación con las actuales.

Los diferentes sistemas médicos, de diferentes culturas o de diferentes momentos temporales, se estructuran alrededor de imágenes legitimadas culturalmente que determinan los modelos explicativos de enfermedad y las prácticas de tratamiento. Siguiendo esta línea, tenemos presente que la enfermedad sucede siempre en un sistema concreto de la medicina. Este como un sector legítimo de la realidad social produce intervenciones específicas de tratamiento, donde cada sistema concreto de medicina generarásus prácticas correspondientes.

La metodología que llevaremos a cabo para analizar el Caso Semmelweis seguirá el modelo de estudios de caso. Se dividirá, por un lado, en el estudio de la biografía del doctor Semmelweis como fuente histórica tomada del libro de Celine (1968), contrastada con los datos biográficos de la Historia Universal de Medicina (1974, p.353-358). También consideraremos la obra del Dr. Beruti (1939) sobre la que intentaremos una aproximación etnográfica. Esta obra fue escrita a setenta años de la muerte de Semmelweis, por el director del Departamento de Obstetricia y Ginecología del Hospital de Clínicas dentro 
del marco de unas jornadas dedicadas a su memoria. Nos resultó relevante que, a pesar de la óptica humanística que valoraba la preocupación por el sufrimiento de las mujeres, insistía en las particularidades de la personalidad del médico húngaro como origen de los problemas que enfrentó, además contaba con referencias muy valiosas sobre la correspondencia entre Semmelweis y sus amigos. Por otro lado, extenderemos el análisis para profundizar y contextualizar los aspectos de la práctica médica como proceso histórico y la construcción de la profesión médica.

El caso Semmelweis se produce en un momento de convulsiones políticas, en medio de las cuales el Imperio Austrohúngaro, entendido como formación histórica, sufría los vaivenes de las decisiones austriacas. Recordemos que el territorio conocido hoy como Hungría fue dominada por el pueblo magiar de Asia hasta mediados del siglo XIV, cuando comienza a regir la casa de Austria. Rodolfo de Habsburgo, emperador de Alemania, fundó esa dinastía y fue uno de los sucesores de Carlos V. El rey Carlos V reunió a las coronas de España y Austria y cedió Austria a su hermano Fernando I. Éste, a su vez, heredó de su esposa el reino de Bohemia y Hungría, país que logró su autonomía con la revolución de 1848. Sin embargo, desde entonces ambas naciones constituyeron la monarquía dual austrohúngara. Hungría, a pesar de ser la parte más débil de esta alianza, tenía instituciones propias.

\section{El caso Semmelweis}

Ignaz Semmelweis nació el 18 de julio de 1818 en Hungría. En 1837, dejó Budapest para conseguir en Viena la licenciatura en derecho austriaco. Luego de un tiempo, se entusiasmó con un curso de medicina en el hospital, lugar en el que contactó al erudito y prestigioso Dr. Skoda, quien fue su profesor y mentor. En esta época conoció también al Dr. Rokitansky, profesional que enriqueció el pensamiento de Semmelweis con su método científico.

Semmelweis no era aceptado por su acento húngaro que lo convertía en objeto de burlas. En 1839, retornó a Budapest para descansar por su estado depresivo y se inscribió en la escuela de Medicina de Budapest, sin embargo encontró la enseñanza de allí poco estimulante. En pleno período Romántico, la formación de los Estados Nacionales exacerbaba los fundamentalismos nacionalistas y todos aquellos rasgos que hacían visible la diferencia se convertían en un estigma. En este contexto, su acento húngaro se convirtió en su estigma. El rasgo estigmatizante muestra las dos caras de una misma moneda: por un lado, el conflicto de identificación entre un nosotros y un ellos y por el otro lado indica que el portador de ese rasgo es inevitablemente reconocido y por lo tanto descalificado (Goffman, 1995). 
En 1841, finalmente volvió a Viena con sus antiguos maestros y se relacionó con el botánico Bozatov que lo entusiasmó con la herboristería, tema sobre el que desarrolló su tesis y obtuvo su título de Doctor en Medicina en la primavera de 1844. Ese mismo año, Semmelweis se recibió de profesor de cirugía y perdió el concurso para ayudante. Ala espera de otra oportunidad permaneció en la clínica donde mantenía un contacto fluido con el Dr. Rokitansky, cuyo trabajo estaba relacionado a las infecciones en procesos quirúrgicos. En 1845, sin posibilidades de nombramiento, cambió su especialidad a obstetricia. Cuando el Dr. Klin solicitó un ayudante, le ofrecieron a Semmelweis, pero éste necesitaba los diplomas obligatorios. Así, en 1846, consiguió superar las pruebas en dos meses y fue nombrado profesor ayudante en la cátedra de obstetricia del doctor Klin, en el hospital general de Viena, donde éste dirigía uno de los pabellones de maternidad.

En medio de las convulsiones políticas del Imperio Austrohúngaro, el Dr. Klin se veía beneficiado por gozar de los favores de la corte austriaca. El contexto de estas convulsiones era parte del anuncio de lo que serían las revoluciones burguesas de 1848 que recorrieron toda Europa. Todas ellas eran revoluciones burguesas, pero en cada lugar mostraban particularidades propias de cada sistema político entendido como construcción histórica.

Los pacientes de ambos pabellones del hospital en que trabajaba Semmelweis eran mujeres encintas de los barrios populares. Semmelweis observó que la mortalidad debido a la infección de fiebre puerperal era mayor en el pabellón donde él trabajaba que en el pabellón liderado por el Dr. Bartch. Esto ya era de conocimiento popular y, por eso, las mujeres se negaban a atenderse allí. La admisión de mujeres se efectuaba por turnos de 24 horas en cada pabellón. Por entonces, la existencia en Europa de las llamadas epidemias de fiebre puerperal había provocado que Luis XIV, en Francia, convocase comisiones para investigar la fiebre puerperal. Esta comisión determinó que la causa de la fiebre era la leche, con lo cual el Colegio de Médicos de París logró que se propusiera al rey la clausura de las maternidades y se suspendiera el servicio de las nodrizas.

La fiebre puerperal estaba matando un 13\% de las mujeres que daban a luz en el hospital en el que trabajaba el Dr. Semmelweis. Hacía tiempo que él estaba preocupado y no podía entender cómo en el otro pabellón atendido por comadronas, sólo el 2\% de las pacientes morían de fiebre puerperal. Hasta ese momento, a nadie se le había ocurrido conectar los gérmenes con la enfermedad. En esa época, en la que la medicina no tenía medios cientííicos "el pensamiento médico involucraba doctrinas no verificadas" (Conrad y Schneider, 1960, p. 52). Las explicaciones médicas que se daban por las muertes por infecciones sostenían que la causa estaba en el "pus trabado", el "pus buena especie" y el "pus laudable". 
Las hipótesis explicativas que se manejaban en el ámbito académico para explicar las causas de la fiebre puerperal, según cita Celine (1968), eran:

1) Si se morían menos pacientes en el pabellón liderado por el doctor Bartch, era porque en ese pabellón el tacto a las parturientas era practicado por las comadronas. Mientras tanto, en el hospital liderado por el doctor Klin, en el que también trabajaba Semmelweis, los que practicaban el tacto eran los estudiantes. Ellos practicaban esa maniobra sin ninguna suavidad, provocando a las parturientas una inflamación fatal. Para probar esta hipótesis, se hizo una rotación de estudiantes y comadronas por ambos pabellones, resultando esta prueba en un aumento de muertes en el pabellón del doctor Bartch. Ante este resultado, el doctor Bartch, retiró a los estudiantes y se quedó sólo con las comadronas. Por su parte, el doctor Klin intentó explicar estas evidencias. Según él, y cabalgando sobre los prejuicios de la época, eran sólo los estudiantes extranjeros los que provocaban la fiebre puerperal. En consecuencia, se redujo el número de estudiantes debido a la segregación de los extranjeros. Si bien, con esto, las muertes llegaron a disminuir momentáneamente, el hecho invariable era que se producían más muertes en el pabellón del doctor Klin que en el del doctor Bartch. Peor aún, se producían más muertes en el hospital que en los partos ocurridos en las calles de la ciudad.

2) La otra hipótesis de carácter oficial que se manejaba, sostenía que era la campanilla del sacerdote la que provocaba un estado de ansiedad en las parturientas y las predisponía a los ataques de fiebre puerperal. Por este motivo se procede a suspender el uso de la campanilla lo que, por supuesto, no alcanzó mayores resultados.

3) Otro tipo de explicación era que las mujeres solas se encontraban más deprimidas al llegar al parto.

En contra de todas estas explicaciones, Semmelweis observó que las mujeres sorprendidas por el parto en la calle y que iban a la clínica en el último momento casi siempre se salvaban, incluso en las llamadas "épocas de epidemia". Ante la falta de respuestas satisfactorias, Semmelweis le pidió a su viejo profesor, el Dr. Rokitansky, que le enviara un médico para efectuar las autopsias y cortes de tejidos cadavéricos de las mujeres que morían. Semmelweis decidió implementar el lavado de manos entre todos los estudiantes antes de acercarse a las parturientas. En octubre de 1846, sus innovaciones e investigaciones lo llevaron a discutir con el Dr. Klin, lo que terminó la destitución de Semmelweis de la clínica.

El profesor Skoda lo protege y lo envía a Venecia junto a su amigo Markusovsky. Skoda, en cierta medida, avala la decisión de Klin, conoce su influencia en la corte y no 
puede arriesgar su prestigio. Finalmente, después de dos meses de descanso, Semmelweis regresa a Viena, donde se entera de la muerte de su profesor de anatomía, Jacob Kollestcha, a causa de una infección por una herida producida durante una disección. Sin dudarlo, Semmelweis asocia la infección de su amigo con los síntomas observados en la fiebre puerperal. A partir del momento de la muerte de su amigo, Semmelweis empezó a notar que los estudiantes se movían entre la sala de disección y la sala de parto libremente, sin lavarse las manos. La trágica muerte de su amigo lo llevó a armar el rompecabezas, deduciendo finalmente que la fiebre puerperal, en realidad, era causada por pequeños agentes invisibles contenidos en el material cadavérico y que eran introducidos a las parturientas por sus médicos que venían directamente de la sala de autopsias.

El Dr. Semmelweis asocia: si los exudados de una disección cadavérica provocaron la muerte de Kollestcha, la causa de contagio estaba en las manos de los estudiantes que se contaminaban durante las disecciones e introducían esas células cadavéricas en los órganos genitales de las parturientas. Es decir, a la hora de practicar el tacto a las parturientas, los médicos les pasaban todos los gérmenes que provenían de los cadáveres. Las manos de los médicos eran, por lo tanto, el vehículo de microbios. Como en esa época el único modo de reconocer las células cadavéricas era por el olor, el doctor Semmelweis establece como política que los doctores debían lavarse las manos en una solución desodorante de cloruro de lima, allí donde ellos finalizaban las disecciones de los cadáveres.

Para probar su hipótesis, era necesario que Semmelweis volviese a practicar en la maternidad. En 1847, Skoda da una muestra más de su estima hacia Semmelweis y con su influencia consigue que Bartch, médico jefe de la otra maternidad, lo reciba como asistente suplente. A pedido de Semmelweis se rotan los alumnos del pabellón de Klin al de Bartch a cambio de las comadronas. Con este movimiento de gente, Semmelweis prueba que la mortalidad sube en un 18\% en relación al índice del mes anterior en el pabellón de Bartch. Luego de esta comprobación continúa con la idea técnica de desodorización y hace preparar una solución de cloruro cálcico con la que debían lavarse las manos los estudiantes que hubiesen diseccionado ese día o el anterior. También establece que quienes fueran a hacer el reconocimiento de cualquier mujer embarazada, deberían lavarse las manos previamente en esa solución.

Semmelweis escribe: "Las manos por su simple contacto pueden ser infectantes" (Celine, 1968, p.109). Apoyándose en esta conclusión, impone el lavado de manos con la solución para todos los doctores y estudiantes, antes de revisar a las mujeres próximas a parir, hayan o no diseccionado. La mortalidad por fiebre puerperal cayó a un 2\% durante el primer mes en que se implementó la obligatoriedad del lavado de manos. Con esta política las muertes bajan a un $0,23 \%$. 
Extrañamente, Semmelweis no hizo ninguna divulgación del éxito de la implementación de esa práctica. Su silencio sólo es comprensible si consideramos que el director del hospital donde trabajaba Semmelweis sintió que su liderazgo había sido criticado por un simple ayudante y, furioso, bloqueó la promoción de Semmelweis. Mientras la mayoría de los médicos de la Facultad de Medicina encabezados por el Dr. Klin estaban en contra de Semmelweis, a favor de él estaban los doctores Rokitansky, Heller, Hebra, Helm y Skoda. En Praga, el Dr. Beyfet dice experimentar durante cinco meses los métodos propuestos por Semmelweis y declara que los resultados obtenidos no concuerdan con los señalados. Apoyado en esto lo trata de impostor.

En 1848, Europa se convulsiona frente a la Revolución de febrero en París y las barricadas de Berlín de las que participa Virchow son: "Las graves y poderosas tormentas que rugen sobre la porción pensante de Europa, sacudiendo los fundamentos de todos los elementos del Estado". Así lo describe en el manifiesto publicado en el primer editorial de la revista "La Reforma Médica" que el propio Virchow edita en sociedad con R. Leubuscher, en julio de 1848." (Rosen, 1985, p.13). Hungría formaba parte de este atolondrado político, en el que Semmelweis, de regreso en su ciudad, se rodea de intelectuales y vive intensamente sus sentimientos patrióticos. En Budapest, desde 1848, la dictadura militar llevó al destierro a los intelectuales - entre ellos al Dr. Semmelweis -, al encarcelamiento del director de la Universidad de esa ciudad y a la prohibición de revistas científicas. En ese contexto, se autoriza una única Sociedad Médica de Hungría ubicada en Budapest bajo la supervisión de un comisario de policía.

En 1849, en un acto de deshonor público, Semmelweis es insultado por enfermeros, estudiantes y enfermos, cansados de esos "lavatorios malsanos". En marzo de 1849, el doctor Semmelweis es destituido por segunda vez. Ese mismo año, en la reunión de la Sociedad Médica, se producen tumultos entre los defensores y los detractores de Semmelweis. Sus amigos comienzan su defensa en otro ámbito, es decir, en la Academia de Ciencias. AllíSkoda envía una nota exponiendo los resultados favorables obtenidos por Semmelweis en un experimento sobre la infección de la fiebre puerperal en animales. Hebra declara en la Sociedad Médica de Viena: "que el descubrimiento de Semmelweis presenta interés para el porvenir de la cirugía y la obstetricia", por lo que solicita que se forme una comisión para analizar los resultados de sus investigaciones. Sin embargo, el Ministro la prohíbe y ordena que Semmelweis abandone Viena. Otras comunicaciones exponiendo su descubrimiento fueron enviadas a Edimburgo, Berlín y Praga. En esta última ciudad tras dos intentos de aplicar el método descrito por Semmelweis declararon que no habían logrado los mismos resultados.

Mientras tanto, el doctor Semmelweis vuelve a Budapest. Allí, el incidente que 
tiene con la condesa de Gradinish - a quien diagnostica correctamente pero faltando a las normas de protocolo y de cortesía - hace con que pierda numerosos pacientes entre las grandes familias de Hungría. En junio de 1849, apenas puede subsistir con el ejercicio de la medicina, pero con la ayuda de sus amigos se salva de morir en la miseria. Gracias a la recomendación de Skoda, lleva sus métodos a un lejano hospital de provincia, la maternidad del Dr. Birley. Allí implementó sus métodos y logró disminuir la fiebre puerperal a menos del 1\% y, además, llegó a aislar sistemáticamente las causas de las muertes. Para esto, hacía la autopsia de las víctimas, establecía grupos de control y trataba de elaborar estadísticas.

Finalmente, Semmelweis presentó el resumen de sus trabajos sobre su método en la Academia de Medicina de París, con resultado adverso. Los debates fueron secretos y la comisión constituida para evaluar nuncase expidió [sic]. Para esaépoca había comenzado a lavar los instrumentos médicos tanto como sus manos. En 1856, tras la muerte del Dr. Birley, Semmelweis lo sucede en la dirección de la maternidad. Aprovechó este nuevo cargo para enviar una carta al periódico, dirigida a los tocólogos de su hospital acusándolos por no usar sus métodos:

“...Asesinos llamo yo a todos los que se oponen a las normas que he prescrito para evitar la fiebre puerperal. No es necesario cerrar las salas de maternidad para que cesen los desastres que deploramos, sino que conviene echar a los tocólogos, ya que son ellos los que se comportan como auténticas epidemias..." (Semmelweis Apud Celine, 1968, p.141).

Durante los años 1857, 1858, 1859 subió el porcentaje de muertes por infección. Este dato sólo es explicable por el boicot realizado contra el Dr. Semmelweis, tanto de doctores como de enfermeros que se negaban a usar su método. Para demostrar su equivocación, deliberadamente, las prescripciones de Semmelweis no fueron observadas por los profesionales. En esa misma época, el consejero municipal del ayuntamiento le hace llegar una carta negándole el presupuesto para una compra de 100 sábanas: "Compra inútil, ya que bien pueden tener lugar varios partos, a continuación unos de otros, en las mismas sábanas" (Celine, 1968, p.143).

El Dr. Arneth es el único amigo que permanece firme, pero carece de apoyo oficial. En marzo de 1858, éste viajó a París llevando el manuscrito del Dr. Semmelweis. Allí, el Dr. Dubois, en una comunicación lapidaria, escribe:

"Esta teoría de Semmelweis, que, como probablemente se recordará, provocó tan violentas polémicas en los medios obstétricos, tanto en Austria como de otros países, parece haber sido abandonada, incluso por la escuela que la profesa. (...) Quizá contenía algunos buenos principios, pero su aplicación minuciosa presentaba tales 
dificultades que hubiera sido necesaria, en París por ejemplo, poner en cuarentena al personal" (Celine, 1968, p.147).

Finalmente, en 1861, Semmelweis escribió un libro sobre sus métodos: La etiología de la fiebre puerperal. Sin embargo, manteniendo la creencia tenaz de que "todo lo que no se ve no existe", la comunidad médica rechazó la teoría de la asepsia propuesta por Semmelweis y no se valoraron sus esfuerzos. En 1865 sufrió un ataque de nervios, por lo que sus amigos lo internaron en una institución mental. Durante su internamiento y pocos días después de haberse cortado un dedo, Semmelweis, en sus tempranos cuarenta y siete años, murió de la misma infección que mató a su amigo Kolletschka y de la misma que él había salvado a miles de madres.

Lo que hoy parece formar parte del sentido común, en ese momento fue una declaración nueva y atrevida contra la ortodoxia de la escuela de Medicina de Viena. La teoría de Semmelweis se demostró o fue probada sólo cuando fueron publicadas las obras de individuos como Koch, Pasteur y Lister. El mismo año de la muerte de Semmelweis, 1865, Joseph Lister comenzó a vaporizar una solución de ácido carbólico durante las cirugías para matar gérmenes. Al final, Lister le da a nuestro infeliz héroe su reconocimiento, al otorgarle el crédito de sus logros (Risse, 1970-1980).

\section{La Teoría Humoral:}

El primer conjunto orgánico de conocimientos médicos del que se tiene noticias es el corpus hipocraticum, grupo de escritos de los siglos VI y V a.C., en el cual se recogen todos los progresos conseguidos por la medicina ateniense. La importancia de este "primer manual médico" radica en el hecho de que su contenido referente a la medicina se aparta claramente de todo planteamiento mágico-religioso. Los estudios médicos recién empiezan a cobrar un nuevo impulso a partir del reencuentro con el mundo árabe que, hasta el siglo XI, ostentaba la primacía de las ciencias. Consecuencia de este encuentro son las escuelas de Salerno y de Montpellier que contribuyeron a la difusión de la cultura médica y a la elevación del nivel general.

En la segunda mitad del siglo XIV se registran progresos en patología. Ya en el siglo XVI, algunos médicos, valiéndose del método experimental que comenzaba a extenderse tímidamente en todos los campos de la ciencia, tratan de abrir nuevos caminos en fisiología y anatomía. De ahí que las estrategias terapéuticas de curanderos y Galenistas combinasen fármacos paliativos o mágicos, sangrías, medidas generales de cuidado y dejar hacer la voluntad del señor. Compartían rasgos comunes con otros curadores puesto que eran más adivinadores que terapeutas y más mediadores que curadores (Comelles, 1994). 
Desde el siglo XVII y hasta la época de Semmelweis, las técnicas usadas para el diagnóstico eran tres: 1) lo que el paciente decía sobre sus propios síntomas; 2) las observaciones que el médico hacía sobre la conducta y la apariencia del enfermo; 3) el examen manual, siendo que ése era el menos frecuente. Aunque los médicos reivindicaban la tradición hipocrática e institucionalizaban el juramento, éste como ritual iniciático no existió hasta principios del siglo XX.

Amediados del siglo XIX, la profesión médica estaba formando sus estructuras y ya existían academias científicas y escuelas de medicina. Existía una incipiente normatización de la profesión. En aquel momento el prestigio pasaba por el poder político individual (submodelo médico privado individual) ${ }^{1}$, como el del Dr. Klin, quien gozaba de los favores de la corte. Pese a esto, en un contexto desfavorable formado por las convulsiones políticas y los prejuicios nacionalistas, Semmelweis se atrevió a adjudicarle a la conducta de los médicos un carácter perjudicial, convirtiéndolos en el vehículo de la propia enfermedad. Aquí encontramos algunas de las razones de su fracaso.

\section{Teoría del Germen}

La relación entre microbios y enfermedades la descubrió casualmente Francesco Redi (1626-1698), comprobándola en la sarna de su perro, que reveló su naturaleza parasitaria. El problema de las infecciones de las heridas sólo se resolvió cuando se logró conocer las causas de las mismas, esto es, después del descubrimiento de los minúsculos agentes patógenos conocidos por el nombre de gérmenes o microbios.

En este sentido, los libros de historia de la medicina no hacen justicia cuando olvidan a Ignaz Semmelweis y hacen especial hincapié en la obra de Louis Pasteur, más específicamente en sus estudios sobre la fermentación. De estos estudios, Joseph Lister pudo observar que si los gérmenes de la fermentación y de la putrefacción pueden transportarse por el aire y depositarse en todos los objetos, la infección de las heridas se produciría por gérmenes que se encuentran en el aire y que contaminan las manos del cirujano y sus ayudantes. Por lo tanto, Lister pensó en rociar de continuo una solución de ácido fénico, tanto en el interior como en los bordes de las heridas cuanto en la atmósfera del quirófano. Esta práctica llamada antisepsia no tuvo un resultado feliz, ya que el ácido fénico es una sustancia nociva para la vida en general. Por esta razón, en la actualidad se prefiere practicar otro tipo de desinfección llamada asepsia. Ese procedimiento consistente en la esterilización general de todo cuanto puede estar en contacto con la herida, desde los instrumentos quirúrgicos, las ropas del cirujano, de sus ayudantes hasta la zona de epidermis donde deba realizarse la incisión.

${ }^{1}$ ver Menéndez (1978) 
Las "victorias" del modelo médico emergente sobre la enfermedad se produjeron en el campo de las enfermedades infecciosas, una vez que se pudieron identificar los agentes causales, es decir, gérmenes específicos. Vemos como el descubrimiento de la teoría de los gérmenes, a mediados del siglo XIX, ha contribuido al éxito y prestigio de la profesión médica (Friedson, 1978).

\section{Análisis del CASo}

En medio de la Revolución Francesa, el problema moral más importante que se coloca para la clínica médica es el derecho de transformar en objeto de observación un enfermo al que la pobreza empuja al hospital (Foucault, 1966). Ya en el siglo XVIII, los médicos ven los aspectos sociales como un elemento para tomar en cuenta en la resolución de los problemas de la medicina y la higiene, pero es sólo en el siglo XIX cuando se desarrolla la idea de la medicina como una ciencia social, es decir, la salud como un problema que la sociedad debe resolver y garantizar a todos (Rossen, 1985).

Hacia mediados del siglo XIX, la práctica médica había pasado de la mirada generalizadora del modelo clínico al vistazo certero. Esta transformación implicaba el cambio entre una mirada que registra y totaliza, basada fuertemente en la prudencia y habilidad individual, en que toda la verdad es una verdad sensible. La nueva mirada es del orden no verbal y descubre un parentesco con un nuevo sentido: el tacto, donde el cuerpo pasa a ser un espacio tangible. Podemos tomar esto como el inicio de una época marcada por Bichat, fundador de la anatomía general, quien va a sustituir el principio de diversificación por el principio de isomorfismo de tejidos, fundado en la identidad de la configuración exterior, la estructura y las propiedades. La anatomía patológica es así el fundamento objetivo e indudable de la descripción de enfermedades, desplazando el acontecimiento patológico sólo alcanzable por la percepción. La mirada médica que hemos visto posarse en los tejidos, no se desprende de los síntomas, sino que para conciliarlos debe incluir la dimensión de lo patológico. Lo patológico no forma un cuerpo sino por la fuerza de la mirada del médico (Foucault, 1966).

Para el siglo XVIII el conocimiento de la vida se apoyaba en la esencia de lo vivo. Apartir de Bichat, el siglo XIX va a incorporar la muerte a un conjunto técnico y conceptual que implicaba, en la práctica, una configuración perceptiva basada en los sentidos: vista / tacto / oído (Foucault, 1966).

Durante el XVIII, el concepto de fiebre era el de una reacción del organismo que se defendía contra el ataque de un agente patógeno, no siendo considerado signo de enfermedad sino de resistencia. A fin del mismo siglo, si bien el factor uniforme es el calor en la fiebre, se descubre, además, que tiene formas específicas. Así se pasa 
epistemológicamente de la fiebre a las fiebres. Como signo, las fiebres presentan un proceso que se desarrolla en el tejido donde hay un ataque funcional y después un ataque de la textura que indica una realidad fisiológica. Es en este momento que Semmelweis emerge a la medicina.

Así como para el siglo XVIII el conocimiento de la vida se apoyaba de pleno en la esencia de lo vivo, para inicios del XIX se integra la muerte. Por entonces, la idea de la medicina como ciencia social se propagaba en Europa en medio de las revoluciones burguesas, con epicentro en Francia, siendo divulgada por médicos como Villerme, Benoiston, Guépin y, en Alemania, por Virchow y Leubuscher. Los principios que sintetizaban los criterios de la medicina social eran: a) la salud como un problema que lasociedad debe resolver y garantizar a todos; b) la relación entre lasalud y las condiciones económicas; y c) los pasos que deberían ser seguidos para combatir la enfermedad y asegurar la salud deberían provenir tanto de la medicina como de los cambios en el orden social. Eran principios basados en las ideas políticas que recorrían Europa, heredados de aquéllas que inspiraron la Revolución Francesa.

Los amigos de Semmelweis llegaron hasta Virchow con sus estudios. El compromiso político que Virchow había asumido con tanto entusiasmo, lo impulsó a abandonar su profesión durante los años en que escribió su revista "La Reforma Médica". Tal vez esto fue un obstáculo para conseguir un apoyo que hubiese sido importante, pero no definitivo para volcar su destino. En la biografía de Semmelweis vemos que, en primera instancia, él actúa de acuerdo con el paradigma aprendido y le pide a su viejo profesor, el Dr. Rokitansky, que le envíe un médico para efectuar las autopsias y cortes de tejidos cadavéricos de las mujeres que morían. "Lo morboso es la forma rarificada de la vida" (Foucault, 1966, p.244). Esto es lo que busca Semmelweis al pedir un patólogo que lo asista, en su intento por hacer visible lo invisible, de aprehender el estado biológico natural. Sin embargo, el dilema que enfrentaba era que, a pesar de que había fiebre y alteración de tejidos, no existía disfunción una vez que el parto había sucedido con éxito.

A partir de la muerte de Kolletschta, Semmelweis realiza una serie de asociaciones que lo llevan a concluir que en ella se encuentra la misma causa de la fiebre puerperal. Probablemente, estas asociaciones estén relacionadas con sus estudios de botánica y con el método de las ciencias naturales para establecer analogías, pero esto cobra sentido una vez puesto en relación con la práctica medica ${ }^{2}$, al comparar el tejido de las mujeres que morían de fiebre puerperal con el de Kolletscha.

\footnotetext{
${ }^{2}$ Nota citada en Foucault (1966): "Me valgo del método de los botánicos [...] que consiste en aproximar objetos que tienen afinidad y apartar los que no tienen analogía” (Alibert, Gnoseologie Naturalle, 1817, Paris).
} 
Las hipótesis de Semmelweis no sólo incitaban a una ruptura con el saber del momento - que cambiaría sólo a partir de la aceptación de la teoría del germen - sino que se convertía en un ataque a la profesión médica. Eso significaba un ataque a esos empresarios morales de la salud (Friedson, 1978) europea que contaban con una estructura burocrática en formación, acompañando al proceso histórico que iba a desembocar en la formación de los Estados-Nación y los modelos de salud que instauraban.

En un momento en que todavía el prestigio de la profesión se basaba en la práctica personal, Semmelweis se levanta con un dedo acusador. El silencio de Semmelweis sólo es comprensible, como nos recuerda Foucault en Historia de la Sexualidad, si el poder se ejerce este ejercicio se basa en la represión, que recae sobre los instintos, la naturaleza y los individuos. "Lo que hace que el poder se sostenga, que sea aceptado, es sencillamente que no sea solo como potencia que dice no, sino que cala de hecho, produce cosas, induce placer, forma saber, produce discursos, hay que considerarlo como toda una red productiva que pasa a través de todo el cuerpo social en lugar de como una instancia negativa que tiene por función reprimir" (Foucault, 1983, p.137). La indagación acerca de los mecanismos de represión de aquella época es lo que nos permite comprender las razones por las cuales su trabajo escrito no vio la luz sino hasta pasados varios años de su descubrimiento (Foucault, 1979). Efectivamente, es con la muerte del doctor Birleyhecho que lo lleva a asumir la dirección de esa maternidad - que no siente la represión del poder sobre él y procede a escribir su libro "La etiología de la fiebre puerperal."

Semmelweis, con su aporte crítico, coadyuva a ubicar la medicina sobre una base más científica, ya que es con la emergencia de la medicina científica - basada en la teoría de los gérmenes - que logra desarrollarse el paradigma hegemónico de la práctica médica. Hasta entonces, no había un modelo organizado de medicina tal y como lo conocemos hoy. Antes de que propuestas científicas como las de Semmelweis se afirmaran, la medicina no era todavía una institución que cumpliera funciones claras. En el siglo XIX, el hospital era una prolongación política, social y cultural del espacio doméstico (Comelles, 1994).

En realidad, es entre 1830 y 1900 cuando se generan los cambios económicos que mejorarán - en los países europeos de mayor desarrollo, especialmente Inglaterra - las condiciones de salud general desde fuera de la medicina. Se produce una mejoría en las condiciones de alimentación e higiene de la población, a la vez que el Estado empieza a intervenir en la salud con el desarrollo de la estructura sanitaria para el aprovisionamiento de agua potable (Menéndez, 1989).

El conflicto se produce al confrontar los resultados de los dos tipos de prácticas, cuando la hipótesis de Semmelweis establece diferencias entre la práctica que se maneja 
domésticamente y la práctica que tienen aquéllos formados académicamente para curar. Semmelweis expresa el quiebre de un paradigma de ejercicio práctico y teórico de la medicina y propone un método de validación basado en los datos sobre los hechos.

Con la ayuda de este caso, podemos ver que mientras el proceso salud / enfermedad / atención ocurre en todas las sociedades, la forma en que éste se realiza varía a través del tiempo y las distintas culturas (Menéndez, 1978). En el caso Semmelweis se puede ver también cómo éste proceso se resemantiza según el contexto histórico. Con esto, queremos decir que si bien el proceso salud / enfermedad / atención, al momento de aparecer Semmelweis en escena, estaba conformado para proceder a tratar a los pacientes y explicar las fallas de los tratamientos. De cierto modo, se produce una retroalimentación positiva en el sistema y eso produce un cambio en el modo de aprehender la enfermedad. Cambia el concepto de enfermedad al encontrar una nueva explicación: su incipiente teoría del germen que rompe con las normas establecidas. Hay una variación en el significado de la enfermedad y, por lo tanto, en el modo como se habrá de tratar: el enfermo se constituye en el hecho en que se va a basar el dato y que, por su vez, es la misma muerte. Siguiendo esta línea, es demostrativo del ímpetu positivista de Semmelweis intentar corroborar su hipótesis solicitando la rotación de las comadronas por los estudiantes, ya sabiendo de antemano que el resultado positivo de su hipótesis es el aumento de las muertes de las parturientas en el pabellón del doctor Bartch. Sin embargo, esta prueba contundente no produce los resultados esperados.

De este modo, vemos como cualquier evidencia observable puede explicarse acomodándose a las hipótesis que arroja el modelo epistemológico al que uno se adhiere. Desde esta perspectiva, el hecho se constituye en un evento producido por el ojo del observador (Ceberio y Watzlawick, 1998). La teoría de la fiebre puerperal epidémica que se sostenía en ese momento era un modo de enunciar la enfermedad que reflejaba el pasado con su historia de humores y fantasmagorías "no visibles" chocando con los hechos de Semmelweis. Además, al mostrar que la enfermedad era una infección que se producía por la falta de higiene de los médicos, él pone en evidencia que se tomaba el síntoma (la fiebre) por la enfermedad (la infección).

En este caso, decir que la enfermedad se producía porque los médicos vehiculizaban los gérmenes del material cadavérico hacia las mujeres prontas a dar a luz, pone por un lado la explicación en los gérmenes, generando ya de por sí toda una teoría inédita de la que hasta entonces no se tenía idea. Por otro lado, también se pone - en gran parte - la culpabilidad en los profesionales de la salud, los doctores. Así, se entiende por qué Semmelweis se ve tan obstaculizado al no ser discutido su descubrimiento, sino el hecho ineludible de que eso cuestiona la práctica médica tal y como se la conocía. Además, a 
través de la práctica se cuestiona la mirada que la medicina tenía en ese momento. A la vez es dentro del contexto histórico de convulsiones políticas que Semmelweis representa la marginalidad política del grupo más vulnerable del Imperio Austrohúngaro.

Si como dice Cicerón "el hombre que devuelve la salud a un semejante es el que más se parece a un dios" (apud Comelles, 1994), nos preguntamos qué le corresponde al responsable de la enfermedad. Quizála respuesta esté en la carta de Semmelweis dirigida al Dr. Scanzoni, figura prominente de la obstetricia europea: "Su doctrina, profesor, está basada en los cadáveres de las parturientas muertas por ignorancia. Si usted cree que mi teoría está equivocada, lo desafío que me comunique y me dé sus razones [...] Pero si usted continuara sin haber rechazado mi teoría, enseñando a sus discípulos la teoría de la fiebre puerperal epidémica, yo lo declaro a usted un asesino ante Dios y ante el mundo." (Danforth, 1986, p.124).

\section{Conclusiones}

Hasta bien entrado el siglo XIX los embarazos y los partos eran un territorio poco explorado por la medicina oficial. Prueba de ello, es que tanto la anatomía como la fisiología de los genitales femeninos comienzan a esclarecerse recién en el período que va desde 1851 a 1908. No existe autor de este período que se resista a discutir sobre la influencia de los antojos en la constitución del feto.

Los descubrimientos del siglo XIX condujeron a grandes avances en el diagnóstico y el tratamiento de enfermedades, tanto como de los métodos de cirugía. Rudolf Virchow fue un pionero en el desarrollo de los estudios en patología y mostró que todas las enfermedades resultan de desórdenes en las células, unidades básicas del tejido corporal. Por su parte, Claude Bernard enfatizó que un experimento debe ser objetivo y probar o desaprobar una hipótesis, sentando así las bases del método científico usado en nuestros días. Una nueva comprensión de las enfermedades infecciosas hizo de las cirugías un método más seguro. Hasta 1800, los cirujanos operaban con sus ropas de calle, sin siquiera lavarse las manos. Operaban en habitaciones comunes, que no estaban suficientemente limpias. Casi la mitad de los pacientes que sobrevivían a una cirugía morían de infecciones generadas durante la operación.

Semmelweis fue quien mostró que la tasa alta de mortalidad en las mujeres después de dar a luz se debía a agentes infecciosos transmitidos por las manos sin lavar de los doctores. El concepto de infecciones bacteriales había nacido. Sin embargo, debemos resaltar que no se trata de un caso en el que chocan la voluntad del hombre libre contra la fatalidad de la historia. Estamos ante el caso de un hombre que se encontró en una situación sociohistórica en la que estaban dadas las condiciones para que se pudiera 
descubrir la presencia mortal de los gérmenes y las infecciones bacteriales que estos producían. No obstante, se encontró con el infortunio de que no estaban dadas las condiciones para que pudieran reconocérselo: Como el propio Engels escribió, defensivamente, en la carta que enviara a Bloch el 21 de septiembre de 1890: "Somos nosotros mismos quienes producimos nuestra historia, aunque lo hacemos en primera instancia, bajo condiciones impuestas y supuestos muy definidos" (Marx \& Engels, 1974).

Al momento de la investigación de Semmelweis pudimos descubrir la existencia de una línea teórica en competencia con las ideas del momento, la de los contagionistas. Éstos representaban la visión ortodoxa de la medicina y enfatizaban prescripciones profilácticas después de la visita del médico. Para ellos, el camino del contagio iba desde una mujer infectada a una mujer sana. La presencia del médico quedaba entre paréntesis en medio del proceso, llevando la enfermedad. No se concebía la posibilidad, en el nivel de la ideas, de una forma de contagio que involucrase a los médicos y a sus prácticas de acceso a los pacientes. Esto reforzaba la negativa de reconocer su papel en la transmisión de la enfermedad.

Semmelweis se encontró con la desaprobación de la comunidad científica, que fundamenta su éxito en la defensa de la suposición de saber cómo es el mundo, a costos elevados, suprimiendo innovaciones que resultan subversivas. En periodos de ciencia normal, la comunidad científica opone resistencia a los esfuerzos de los miembros más capaces sin embargo, como en el caso analizado Semmelweis, responden a una anomalía del paradigma dominante. En el caso de la fiebre puerperal, a pesar de que había fiebre y alteración de tejidos, no existía disfunción ya que el parto había sucedido sin problemas (Klimovsky, 1997). Todo lo que Semmelweis había aprendido no le servía para explicar el desarrollo de la fiebre puerperal, que seguía provocando la muerte del $30 \%$ de las mujeres que daban a luz en el hospital.

Semmelweis no tuvo éxito con su teoría y su propuesta aséptica. La mayoría de los libros de historia de la ciencia nos muestra el progreso como una sumatoria lineal de descubrimientos, de procesos graduales y sucesivos, siempre negando el conflicto entre paradigmas. El Caso Semmelweis demuestra, una vez más, que la historia de la ciencia no es la historia de los descubrimientos, sino la historia del poder. No se trata tanto de un positivismo científico, sino de un fundamentalismo de escuelas teóricas en disputa.

Siguiendo la argumentación de Foucault (1979) acerca del ejercicio del poder, este autor establece una distinción entre prohibición y represión. Mientras la primera impone una norma clara y específica sobre aquello que no debe hacerse; la segunda obliga al silencio e instala una afirmación de inexistencia que implica que no hay nada 
que decir o saber sobre alguna cosa (Foucault, 1990). Este es el mecanismo que se impone, una y otra vez, tanto a Semmelweis como a sus amigos en sus intentos por exponer y dar a conocer la investigación sobre la fiebre puerperal. Las burlas y los escándalos que suceden en los ámbitos académicos de la época son la cara visible de la represión que silencia a los que se oponen al poder del saber establecido, es decir la represión como lazo que vincula el poder y el saber.

Los avatares en la configuración y transformación de la organización política húngara, acompañando las subidas y bajadas políticas austriacas, también pueden verse expresadas en la historia de Semmelweis. Como nos dice Williams (1980, p.107): "la sociedad nunca es una 'cáscara muerta' que limita a la mediación social e individual. Es siempre un proceso constitutivo con presiones muy poderosas que se expresan en formaciones culturales, económicas y políticas (...) que son internalizadas y convertidas en 'voluntades individuales"'.

Del mismo modo, Darwin y Wallace nunca supieron que trabajaban sobre la misma teoría de la evolución de las especies. Encontramos en Estados Unidos al doctor Oliver Wendel Holmes que tres años antes que Semmelweis comunica a la Boston Society for Medical Improvement la transmisibilidad de la fiebre puerperal. Prescribe un límite en la duración de la exploración por tacto, implanta el cambio de ropa en el personal asistente al parto y establece el lavado de manos. Adiferencia de Semmelweis que introduce la asepsia a través del lavado con agua clorada, Holmes no especifica si la transmisión de la enfermedad se producía a través del aire o era por transmisión directa.

Finalmente, la era de la cirugía aséptica es atribuida al cirujano inglés Joseph Lister, quien con su introducción del ácido carbólico logró reducir la mortalidad producida por infecciones. Más allá del reconocimiento que Lister ${ }^{3}$ hace del trabajo de Semmelweis, este último queda ligado y limitado a la fiebre puerperal en su aporte científico al campo de la obstetricia.

Lo interesante en el caso Semmelweis es que, al examinar una situación o caso aparentemente atípico, pudimos descubrir normas no expresadas. Tal como recuerda Thompson E.P. (1992, p.64) "[...] el estímulo antropológico surte efecto [...] en la localización de problemas antiguos con ojos nuevos [...] y en la atención de las expresiones simbólicas de autoridad, control y hegemonía". Poder entrelazar la historia breve en cuanto coyuntura, es decir, los episodios de la vida de Semmelweis con la historia larga, nos permite incorporar el concepto de proceso en el cual es posible contextualizar la ambigüedad de un modelo médico en formación. En este caso, la historia larga enmarca

\footnotetext{
3 "Creo con gran admiración hacia él y su descubrimiento y me lleno de satisfacción que al final reciba el respeto debido" (Enc. Britannica, 2003 ed.), traducción del autor.
} 
la convulsión política del Imperio Austrohúngaro. Contempla, también, la segunda etapa de la Revolución Industrial que consolida el desarrollo del capitalismo y los modelos políticos que se consolidan hasta desembocar en los estados Nación de fines del siglo XIX, junto a sus modelos higiénicos sanitarios.

Al inicio de este artículo, nos preguntamos qué hizo de Semmelweis un personaje maldito. Enfocarlo desde la práctica médica, tanto en la construcción de la teoría como del quehacer en sí, nos permitió ver qué era lo que cuestionaba la postura desafiante de Semmelweis y hacer explícito, de este modo, cómo este desafío enfrentaba a la ortodoxia médica.

Semmelweis muere en 1865 y sólo a partir de 1875 los textos de divulgación empezarán a indicar la necesidad de que los partos y el cuidado de los neonatos abandonen el ámbito "de lo natural" para ser sometidos a reglas estrictas fundadas racionalmente. Hasta fines del siglo XIX, la gravidez y el parto eran acontecimientos poco medicalizados y poco tecnificados. No obstante, empieza a manifestarse una tendencia al aislamiento de la parturienta que terminará por convertir al acto de parir en un problema médico sanitario y enrolará a todas las comadronas bajo las órdenes de un médico jefe. "Las grávidas abandonaron sus inhóspitos y poco higiénicos hogares para encaminarse a los hospitales [...] que convertirán a los embarazos y alumbramientos en una nueva especie patológica a ser dominada" (Cecchetto, 1995, p.95).

Aquel camino de construcción de la práctica y la teoría médica moderna, iniciado mediados del siglo XIX, cuando el prestigio pasaba por el poder político individual, cruzó el umbral del siglo XX fortalecido y legitimado. Recién en 1929, hay un reconocimiento a Semmelweis cuando le levantan un monumento en Viena con la inscripción: "Al salvador de las madres". En la actualidad, aún se encuentran referencias históricas en tratados de medicina que aluden más al carácter intempestivo de Semmelweis que a su investigación, como causa de sus problemas con la comunidad médica.

En un contexto desfavorable formado por las convulsiones políticas y los prejuicios nacionalistas, Semmelweis se atrevió a adjudicarle a la conducta de los médicos un carácter perjudicial, elaboró teoría y modificó la práctica profesional, señaló a sus colegas como el vehículo de la propia enfermedad. Una suma de las razones de su fracaso y el tamaño de las fuerzas que enfrentó, una historia de la producción del conocimiento científico. 


\section{REFERÊNCIAS}

Beruti, Josue. A. Semmelweis y la fiebre puerperal, obra y vida desventurada de un gran medico. Buenos Aires, 1939.

Biblioteca Temática Uthea. Conquistas de la Humanidad. Tomo II. España: Editorial Hispano-Americana, 1980.

Ceberio, Marcelo.; Watzlawick, Paul. La construcción del universo. Barcelona: Herder, 1998

Cecchetto, Sergio. Medicalización del embarazo y el parto. Cuadernos Medico Sociales, No. 70, Rosario (Argentina), 1995.

Cecchetto, Sergio. Dilemas Bioéticos en Medicina Perinatal. Buenos Aires. Corregidor 1999.

Celine, Louis Ferdinand. Semmelweis. España: Editorial Alianza, 1968.

Comelles, J.; Martinez Hernaez A. Enfermedad Cultura y Sociedad. Madrid: Eudema, 1993.

Comelles, J. La sacralización de la práctica hospitalaria. Del despliegue tecnológico a la institucionalización del milagro. En: Barona, Joseph Luis (Compilador) Seminarios de Estudio de la Ciencia, p.179-206. Valencia: Malaltia i Cultura, 1994.

Conrad, P. Y Schneider, J. Deviance and Medicalization: from badness to sickness. Columbus, Ohio: Merril Publishing Company, 1985.

Danforth, David. Tratado de Obstetricia y Ginecología. 4ta Edición. Versión especialmente dirigida por el doctor P. de la Fuente Pérez. México DF: Interamericana, 1986.

Foucault, Michel. El nacimiento de la clínica: Una arqueología de la mirada médica. México: Siglo XXI, 1966.

Foucault, Michel. Microfísica del poder. Madrid: Ediciones de la Piqueta, 1979.

Foucault, Michel. El discurso del poder. Mexico: Folios, 1983.

Foucault, Michel. The bistory of sexuality. Volume 1: An Introduction. USA: Vintage books Edition, 1990.

Friedson, Eliot. La Profesión Médica. Capítulos XII y XIII. Barcelona: Ed. Península, 1978.

Goffman, Erving. Estigma. Buenos Aires: Amorrortu Editores, 1995.

Hempel, Carl. Filosofía de la ciencia natural. Madrid: Alianza, 1977.

Historia Universal de la Medicina La obstetricia y la ginecología, p. 353-358. Barcelona: Salvat editores, 1974.

Hobsbawn, Eric. J. Las Revoluciones Burguesas. Vol. I. Madrid: Editorial Guadarrama, 1962.

Kleinman, Arthur. Patients and healers in the context of culture. An exploration of the borderland between anthropology, medicine and psychiatry. Berkeley, Los Angeles: University of California Press, 1981. 
Klimovsky, Gregorio. Las desventuras del conocimiento científico. Buenos Aires: A-Z Editora, 1997

Marx, K \& Engels, F. Obras Escogidas, en tres tomos. Tomo III, Moscú: Editorial Progreso, 1974.

Menéndez, Eduardo. El Modelo Medico y La Salud de los trabajadores. En: Basaglia, Franco y otros. La Salud de los Trabajadores. México: Editorial Nueva Imagen, 1978.

Menéndez, Eduardo. Morir de Alcohol. México: Editorial Alianza, 1989.

Risse, G.B. Semmelweis, Ignaz Philipp. Dictionary of Scientific Biography (C.C. Gilespie, ed.). New York: Charles Scribner's Sons, 1970-1980 [sic].

Romero, José Luis. Estudio de la mentalidad burguesa. Buenos Aires: Editorial Alianza, 1993.

Rosen, George. De la política médica a la medicina social. México: Siglo XXI, 1985.

Thompson, E.P. Folklore, antropología e historia social. Revista Entrepasados, No.2. Buenos Aires, 1992 (edición original de 1976).

Williams, Raymond. Marxismo y Literatura. Barcelona: Península Editores, 1980.

Williams, Raymond. Cultura: sociología de la comunicación y del arte. Barcelona: Paidós editores, 1982. 